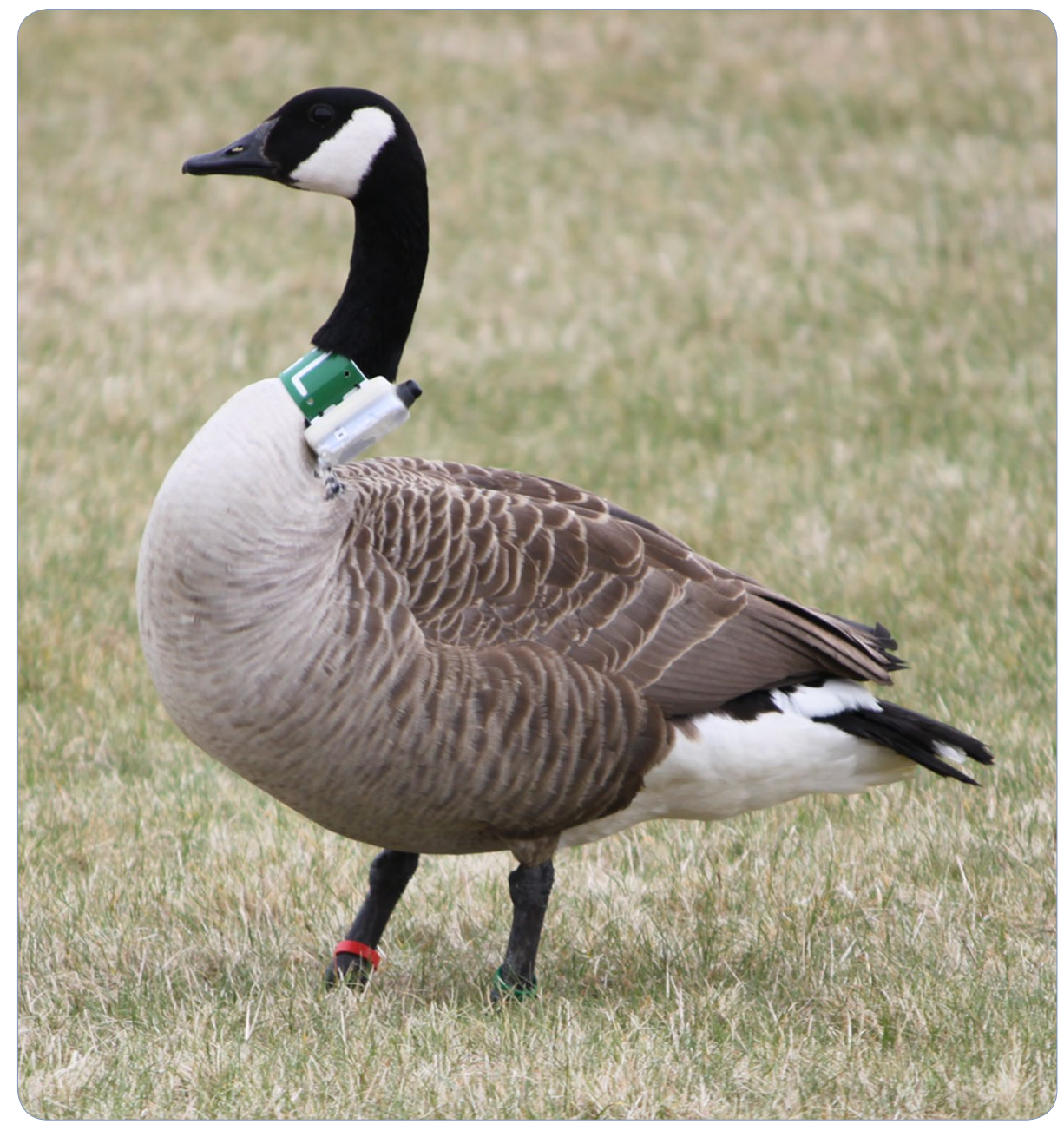

\title{
Neckband or backpack? Differences in tag design and their effects on GPS/accelerometer tracking results in large waterbirds
}

Kölzsch et al. 


\title{
Neckband or backpack? Differences in tag design and their effects on GPS/ accelerometer tracking results in large waterbirds
}

Andrea Kölzsch ${ }^{1,2,3^{*}}$, Marjolein Neefjes ${ }^{1}$, Jude Barkway ${ }^{4}$, Gerhard J. D. M. Müskens ${ }^{5}$, Frank van Langevelde ${ }^{6}$, Willem F. de Boer ${ }^{6}$, Herbert H. T. Prins ${ }^{6}$, Brian H. Cresswell ${ }^{4}$ and Bart A. Nolet ${ }^{1,7}$

\begin{abstract}
Background: GPS and accelerometer tracking presently revolutionises the fields of ecology and animal behaviour. However, the effects of tag characteristics like weight, attachment and data quality on study outcomes and animal welfare are important to consider. In this study, we compare how different tag attachment types influence the behaviour of a group of tagged large waterbirds, GPS accuracy and behaviour classification success from accelerometer data.

Results: Both neckband and backpack tags had similar effects on the behaviour of six captive Canada geese (Branta canadensis), increasing the amount of discomfort behaviour in relation to untagged individuals. Both treatment groups also slightly decreased the amount of foraging, but the duration of neither vigilance nor resting was affected. GPS positions that were filtered with classical GPS platform settings (i.e. smoothing) were more accurate than positions improved by satellite-based differential augmentation. Tag attachment, however, did not induce any differences in position accuracy of both data types. Behaviour classification success was generally similar for neckband and backpack tags. But in detail, behaviours mainly performed by the head like foraging and vigilance were better detected from accelerometer data of neckband tags, whereas behaviours like resting and walking were more successfully detected from backpack tag data.
\end{abstract}

Conclusion: Our findings suggest that the use of neckband or backpack tags for tracking large waterbirds and their behaviour largely depends on which behaviours are most important to detect. However, for wildlife tracking studies, factors like tag retention time are also of great importance, especially for animals like some goose species that are known to quickly destroy backpack tags. For future studies, we advise to carefully evaluate not only tag weight, but also attachment methods and data quality, because the right choice depends on the research question. This will improve the scope of wildlife tracking even more for various scientific, conservation and management applications.

Keywords: Animal tracking, Tag attachment, Tag placement, Tag effects, Differential GPS accuracy, SBAS, Behaviour classification, Accelerometer, Canada goose, Branta c. canadensis

\section{Background}

Animal tracking with GPS has become an important and widely used technique for wildlife research in recent

\footnotetext{
*Correspondence: akoelzsch@orn.mpg.de

${ }^{2}$ Department of Migration and Immuno-ecology, Max Planck Institute for Ornithology, Am Obstberg 1, 78315 Radolfzell, Germany

Full list of author information is available at the end of the article
}

years $[1,2]$. It has matured from being used in simple home range studies to diverse applications examining habitat selection, animal migration, behaviour and physiology [3-6]. This might partly be due to the improved performance of GPS circuits, but also the addition to the tags of auxiliary sensors, like depth metres, light sensors or accelerometers $[7,8]$. Accelerometers in particular are 
revolutionising the field of animal energetics by enabling researchers to determine animal behaviour remotely [912]. Recently, it has even been shown that acceleration data are suitable to determine an animal's internal states, like disease status or stress level [13].

Since the first years of animal tracking, researchers have been aware that study outcomes might be affected by the quality of the tags [14-17] and how the tags affected the animals [18-23]. Fix rate (amount of successfully acquired positions), GPS accuracy (deviation from true location) and precision (measurement reproducibility) were considered repeatedly [24, 25], especially for studies in closed or mountainous habitats $[26,27]$ or for those on fine-scale habitat use [28], social interactions for disease transmission [29] or GPS-based behaviour segmentation and classification [30-32].

In order to improve GPS accuracy, which is one focus of this paper, GPS receiver modules apply smoothing algorithms to the location data before they are output to the user. Typically, these algorithms are based on the extended Kalman filters [33]. These filters rely on a variety of movement models and are sometimes referred to as platform settings [34], the choice of which depends on the expected movements of the object being tracked (e.g. stationary, pedestrian walking, motor vehicle). The constraints imposed by these models can be problematic if different behaviours are to be extracted from the GPS tracking data of free-ranging animals. Only one type of filter can be used for the whole data set, and a pedestrian walking filter, for example, might faultily introduce movement at times that the animal is resting. Other options for accuracy improvement are differential GPS systems [35], i.e. ground- and satellite-based augmentation systems (GBAS and SBAS), which can be applied to the data directly or by post-processing raw GPS data, i.e. satellite pseudo-ranges, protocol RXM-RAW [34]. The latter system is still under development in many countries and presently evaluated [36-38].

GPS fix rate and accuracy have also been shown to depend on the design of the tag, especially on the gain and orientation of the antenna [39]. However, this is only one factor to consider during tag development, especially with respect to affecting the behaviour, physiology or demography of the animal $[20,21]$. Tag weight has received a lot of attention, especially in flying or diving animals $[40,41]$. It is generally agreed that tag weight should be $<5 \%$ (or $<3 \%$ as recently proposed) of the body weight of the animal [42-44]. However, tag shape, attachment and placement can be of equal importance and influence maximum suitable tag weight [18, 45-49]. Depending on body structure, tags are mostly placed on the back (close to the centre of gravity), neck or tail of terrestrial animals and attached by harnesses, collars or glue. For specific research questions, especially involving accelerometer sensors measuring specific body movements, other tag placements have been used (e.g. head [50], scapulae [51]). In this way, the 3D orientation and dynamic movement of specific body parts can be quantified, allowing conclusions about the use of muscles or other motile body parts for certain behaviours or physiological processes.

Until very recently, due to the large size of traditional GPS tags, only the largest birds have been studied with GPS telemetry, most notably swans, geese and large raptors, often focussing on their migration ecology [52-56]. As some goose species are presently of conservation concern, while others are considered pests, the need to improve our knowledge about these species has increased [57]. Swans and geese have been shown to display a variety of adverse behaviours during being handled and after tagging, e.g. increased preening or biting the tag/harness [54, 58-61]. To decrease negative effects of tag aversion [62], it is necessary to shorten handling time and evaluate different types of tag placement and attachment methods for this species group [58, 63-66]. Welfare assessments should be made alongside considerations of data quality in order to balance animal discomfort against the amount and quality of scientific knowledge gained from the respective study [67]. Backpack tags attached with harnesses are the most widely used way of tracking large waterbirds $[59,60]$, but with the recent miniaturisation of GPS tags, it is now possible to also attach or integrate them into neckbands. Numbered plastic neckbands have been successfully used for many years for individual resighting of wild geese and swans [68-71], and for a few years, these have included radio or GPS tags $[54,72]$.

Here, we present a comparison of the performance of neckband and backpack GPS tags in captive geese during early habituation. During six successive days after deployment, we have quantified the effect of both tag types on the birds' behaviour, namely how much their behaviours deviated from control individuals without a tag. Then, we have evaluated GPS accuracy (with GPS platform setting 'pedestrian walking' and/or SBAS) of both tag types, expecting worse performance of the neckband tags, because antenna orientation deviates more often from upwards. Furthermore, the success of classification of different behaviours from accelerometer data was compared and related to the attachment method. Finally, considering different research questions, a framework is presented to inform tag design and placement for future tracking of large waterbirds like swans and geese.

\section{Methods}

\section{Tests with captive geese}

Our experimental animals were six captive, at the time flightless Canada geese (Branta c. canadensis) that were 
held in a group of ten at the outside waterbird facility of the Netherlands Institute of Ecology (NIOO-KNAW). The geese were sub-adults and had not yet formed stable couples. The six focal birds (three males and three females) were selected based on body size, low resistance to being handled and medium to high social position within the group. They weighed on average $5.2 \mathrm{~kg}$ (range $4.2-6.9 \mathrm{~kg}$ ) so that tags up to a weight of $150 \mathrm{~g}$ would be within the more conservative $3 \%$ margin [18] generally accepted for animal tracking.

The tests were performed as three trials, each lasting 6 days, in January-April 2013. During the trial periods, the geese were split into two groups of five individuals, each including three experimental birds. The groups were assembled in a rotational design to account for individual variability of the geese. On the day before the start of a trial, of each group of experimental birds, one was equipped with a neckband tag ( $70 \mathrm{~g}$, including neck ring, able to freely rotate around the goose's neck, Fig. 1a), one with a backpack tag $(80 \mathrm{~g}$, including harness, Fig. 1b) and one was left without a tag as control. The tags were prototypes, programmed to continuously collect GPS positions $(1 \mathrm{~Hz})$ and tri-axial accelerometer measures $(50 \mathrm{~Hz})$ for $2 \mathrm{~h}$ /day, one group in the morning (8:00-10:00 GMT) and the other in the afternoon (11:00-13:00 GMT). They were fitted with helical antennas (Sarantel GeoHelix), which were vertical (pointing upward) on the neckbands and horizontal (pointing forward) on the backpacks. The omnidirectional reception pattern and physical shape of a helical antenna enabled more similar performance between neckband and backpack tags than would be possible with a more conventional patch antenna. By

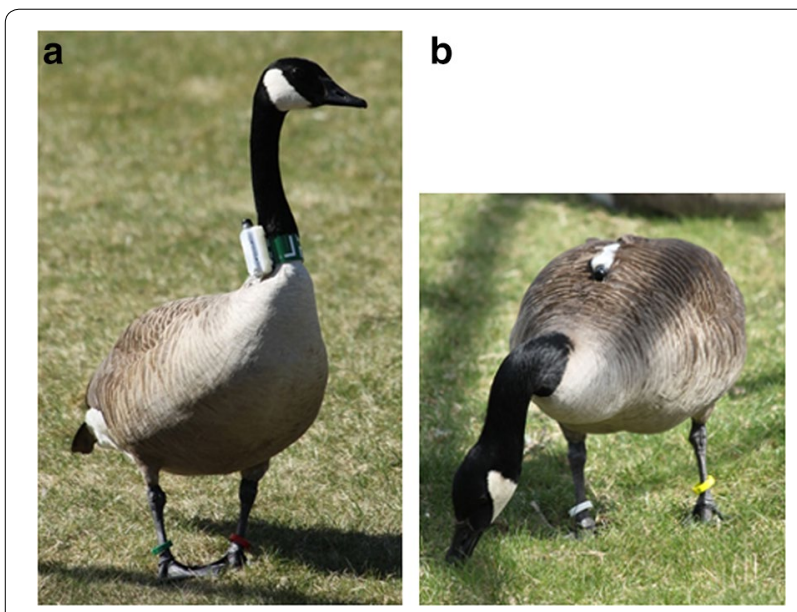

Fig. 1 Prototype tags used in this study, each mounted on a Canada goose: a neckband tag, $\mathbf{b}$ backpack tag. Note the orientation of the tags. The tags were developed by Biotrack Ltd. in the collaborative project E-Track (www.etrack-project.eu). Photography by AK setting different receiver protocols, the tags were activated to receive SBAS signals (from EGNOS satellites) for improved position accuracy as well as to collect raw GPS data for post-processing.

Every day of the trials, the goose groups were observed in a $26 \times 26 \mathrm{~m}$ fenced field located in a wider open area at the times that the tags were recording data. Each of the three experimental animals was observed and its behaviour recorded during three periods of $10 \mathrm{~min} /$ day; the timing of those observations was designed in a balanced rotational grid to correct for the influence of time of day on behaviour. Goose behaviour was recorded live using the Observer XT version 11 software (Noldus IT), and we discerned six main behaviours: feeding, resting, walking/running, vigilance, shaking and preening. Other behaviours were also scored, but were not included in the analyses because of low frequencies. During each 10-min observation period, a second observer recorded the distance $( \pm 2 \mathrm{~cm})$ and angle $\left( \pm 1^{\circ}\right)$ to the lighter breast region of the focal goose (ca. 10-20 cm from the deployed GPS tag) about 5-15 times using a Geosystems Total Station (TCR 307 version 350.24). The device was at a fixed position that had previously been accurately located $( \pm 2 \mathrm{~cm})$ with a DGPS instrument (Ashtech ProMark 800).

\section{Analysis of behavioural observations}

In total, each of the six experimental geese was observed 54 times for $10 \mathrm{~min}$, apart from one bird that had to be excluded during the last 3 days because of feather wear below a small part of the harness. Thus, our data set comprised 315 observation periods. For indication of tag-induced behaviour, we extracted the total duration of preening (including pecking the tag) and frequency of shaking (the head or body) per 10-min observation period. To evaluate likely impacts of tag or tag type on other behaviours, we further examined the total durations of feeding, vigilance and resting per observation period. Effects on these behaviours and possible habituation with time of deployment were tested by comparing generalised linear mixed models (GLMMs, R package 'Ime4') with and without tag type (backpack BP, neckband $\mathrm{NB}$ and control C) and day since deployment as fixed factors and date, individual and sex as random factors by a likelihood ratio test (LRT).

\section{Processing and evaluation of GPS data}

Because of several tag failures, we were only able to use 9 days of GPS data from the backpack tags and 7 days of data from the neckband tags, including 32 of the 10-min observation periods. Thus, the data set for the following analyses comprised $18 \mathrm{~h}$ (61,873 positions) of backpack and $14 \mathrm{~h}$ (47,178 positions) of neckband GPS data, both normally processed locations (aka NMEA data; see list of 
abbreviations) as well as raw GPS data. The NMEA positions were improved by the GPS module under the platform settings of 'pedestrian walking' [34]. Of the NMEA positions, $29.9 \%(\mathrm{BP})$ and $29.6 \%(\mathrm{NB})$ had incorporated SBAS (EGNOS) signals for improved accuracy.

For evaluation of the effect of SBAS improvement independently of the GPS platform settings, we post-processed the raw GPS data with archived SBAS correction files (from the EDAS service, ftp://igs.ensg.ign.fr/pub/ igs/products/), using RTKlib version 2.4.2 with single point positioning mode, an elevation mask of $15^{\circ}$, IONEX TEC Ionosphere Correction, SBAS Satellite Correction and Precise Satellite Ephemeris. The position data set generated was called precise point positions (PPP; see list of abbreviations). The settings were selected as to obtain independent positions without any inference on movement type and on the basis of stationary tests with different elevation masks. Because of gaps in the EDAS data set, only $29.3 \%(\mathrm{BP})$ and $25.9 \%(\mathrm{NB})$ of the GPS positions could be augmented to PPP data.

To determine GPS accuracy of the different GPS position types (NMEA and PPP), we compared them with the rather exact positions that were calculated from the measurements obtained with the Geosystems Total Station. This resulted in the following data sets that coincided in time with Total Station positions: 148 (BP) and 127 (NB) NMEA positions without SBAS augmentation (referred to as NMEA 1; see list of abbreviations), 79 (BP) and 53 (NB) NMEA positions with SBAS augmentation (NMEA 2) and 73 (BP) and 50 (NB) PPP positions. After projection of all positions into the appropriate UTM (Universal Transverse Mercator coordinate system) zone 31, distances between time-overlapping positions were calculated, indicating accuracy of the respective GPS positions: NMEA 1 (with 'pedestrian walking' filter, without SBAS), NMEA 2 (with 'pedestrian walking' filter, with SBAS) and PPP (without 'pedestrian walking' filter, with SBAS). We also calculated minimum convex polygon areas of NMEA and PPP tracks for each 10-min period and compared how SBAS augmentation and the GPS module platform settings (i.e. 'pedestrian walking' filter) influenced the spatial extent of the data sets. Distances and polygon areas were compared between different GPS data sets and tag designs using GLMMs (see above).

\section{Behaviour classification from acceleration data}

Similar to the GPS data, we obtained a data set of 9 days $(18 \mathrm{~h})$ of accelerometer measurements from the backpack tags and 7 days $(14 \mathrm{~h})$ from the neckband tags. The acceleration data could not be recorded continuously at $50 \mathrm{~Hz}$, because of time required intermittently to write data to the tag's memory. Therefore, we down-sampled it to a continuous $20 \mathrm{~Hz}$, which is widely used for studies to classify animal behaviours. All accelerometer data sets were then divided into static acceleration (as moving averages over a sliding window of $2 \mathrm{~s}$ width) and dynamic acceleration (difference between raw acceleration and static acceleration).

Following the workflow of [73], we overlaid accelerometer data and behavioural observations and split the data set into acceleration bursts of the same behaviour. Because of observation delays of about $1 \mathrm{~s}$ (range $0.5-2 \mathrm{~s}$ ), we selected only bursts where the animals showed the same behaviour for $\geq 5 \mathrm{~s}$ (most used periods were longer than $5 \mathrm{~s}$, and using a longer period of $\geq 10 \mathrm{~s}$ did not qualitatively change the results). Thus, the main part of each selected burst showed the targeted behaviour so that influences of delayed scoring were minimised. The selection resulted in a data reduction to $38.5 \%$ (BP) and $25.7 \%(\mathrm{NB})$ of all bursts for analysis, leaving us with 848 (BP) and 537 (NB) behavioural bursts, totalling to $5.63 \mathrm{~h}$ (BP) and $4.21 \mathrm{~h}$ (NB) of behaviour-annotated accelerometer data. Due to this selection, the sample size of shaking (naturally of short duration) became extremely low and we excluded it from these analyses.

For each burst, we calculated the proposed acceleration statistics (see Table 2 of [73], excluding speed) and analysed them with a recursive classification tree algorithm (R package 'rpart'), split by tag type. To avoid overfitting, we pruned both of the resulting classification trees (BP and NB) to their minimum complexity parameter. Their predictive power was finally quantified by prediction accuracy (proportion correctly classified bursts), overall and for each of the behaviours separately.

\section{Results}

\section{Effects of tags on observed behaviour}

Our analyses showed that both tags had an effect on the behaviour of the experimental geese (Fig. 2). Especially discomfort behaviours, like preening and shaking, were significantly increased if the geese were carrying a tag. A goose without tag (control C) would be preening for about $18 \mathrm{~s}$ within a 10 -min period, whereas a goose with a backpack (BP) would preen and peck the tag for c. $83 \mathrm{~s}$ and a goose with neckband (NB) for c. $82 \mathrm{~s}$ (LRT, $x^{2}=37.0, d f=2, p<0.001$ ). Frequency of shaking (in times per 10-min period) increased somewhat for neckband tags (C: 0.3 times, BP: 0.4 times, NB: 1.0 times; LRT, $\mathrm{X}^{2}=26.4, \mathrm{df}=2, \mathrm{p}<0.001$ ). This can be explained by the fact that shaking the head to get rid of the neckband was scored as 'shaking. The extra time spent on shaking when geese wear the neckband was very small relative to the increased preening time. Thus, both types of tags caused extra discomfort to the birds. The geese reacted to backpacks and neckbands differently, but overall used the same amount of time for extra discomfort behaviour. 

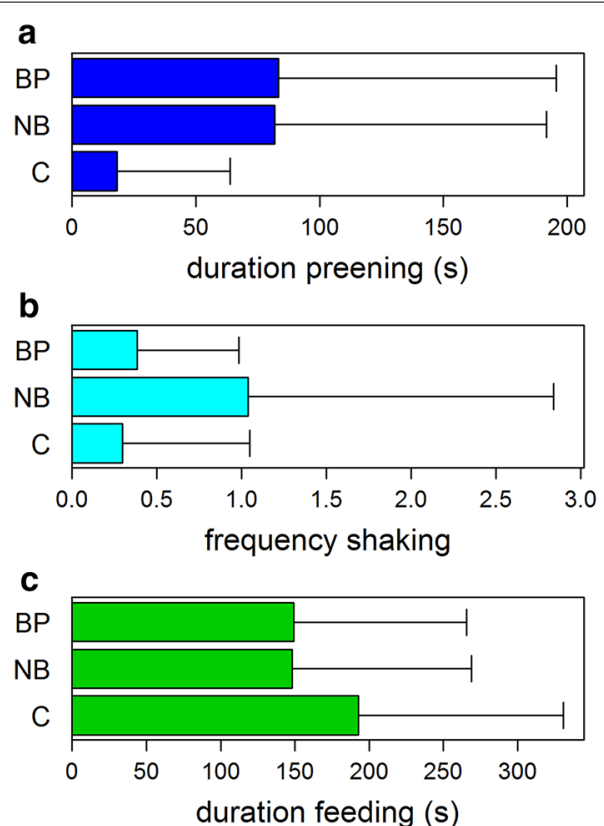

d
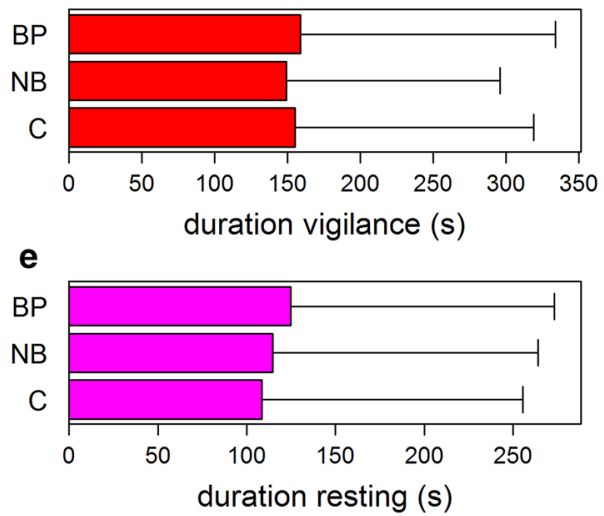

Fig. 2 Bar plots (mean \pm SD) of discomfort levels of geese carrying a backpack tag (BP), neckband tag (NB) or no tag (control C). Behaviours indicating discomfort are a duration of preening (and pecking the tag), $\mathbf{b}$ frequency of shaking (the body or the head), $\mathbf{c}$ duration of feeding, $\mathbf{d}$ duration of being vigilant and $\mathbf{e}$ duration of resting behaviour, each within 10-min periods

Furthermore, a goose with a tag would feed less (C: $193 \mathrm{~s}, \mathrm{BP}: 152 \mathrm{~s}, \mathrm{NB}: 148 \mathrm{~s}$; LRT, $\chi^{2}=11.1$, df $=2$, $\mathrm{p}=0.004)$, but be no less vigilant (LRT, $\chi^{2}=0.2, \mathrm{df}=2$, $\mathrm{p}=0.92$ ) nor rest for shorter times (LRT, $X^{2}=0.8$, $\mathrm{df}=2, \mathrm{p}=0.67)$. There were no differences between the two tag types in terms of duration of feeding, vigilance and resting, indicating that they were similar in the degree to which they affected goose comfort. In addition, there was no effect of time since deployment on the extent of any of the behaviours (LRT, $x^{2}<1$, df $=1$, $\mathrm{p}>0.30$ ), showing that the birds were not yet getting habituated to the tags.

\section{GPS accuracy}

There were various effects of tag type and GPS position type on the accuracy in terms of distance to the (exact) positions as obtained by the Geosystems Total Station (Fig. 3). For NMEA 1 positions, modelled inaccuracy (GLMM model estimate of distance to exact position) was smaller for neckband tags $(1.8 \mathrm{~m})$ than backpacks $(3.5 \mathrm{~m}$; LRT, $\chi^{2}=16.3$, df $\left.=1, p<0.001\right)$, whereas the inaccuracies of NMEA 2 were similar for the two tag types (BP: $2.4 \mathrm{~m}, \mathrm{NB}: 2.2 \mathrm{~m}$; LRT, $\chi^{2}=0.7, \mathrm{df}=1, \mathrm{p}=0.39$ ). Also for PPP positions, the inaccuracy was smaller for neckbands (BP: $3.7 \mathrm{~m}, \mathrm{NB}: 1.9 \mathrm{~m}$; LRT, $\mathrm{x}^{2}=5.4, \mathrm{df}=1, \mathrm{p}=0.02$ ). Consequently, tag type lost its influence on GPS accuracy only if the platform setting ('pedestrian walking') and SBAS enhancement were applied simultaneously. If only one or the other was applied, the neckbands were more accurate than the backpack tags.

When looking at each tag type separately, only the backpacks revealed an effect of GPS position type on accuracy, with the pedestrian walking filter improving accuracy (NMEA 1: 3.3 m, NMEA 2: $3.2 \mathrm{~m}$, PPP: $3.8 \mathrm{~m}$; LRT, $\left.\chi^{2}=7.1, d f=2, p=0.03\right)$. GPS accuracy did not differ by GPS position type, and effect sizes were smaller for neckbands (NMEA 1: 2.5 m, NMEA 2: $2.1 \mathrm{~m}$, PPP: $2.4 \mathrm{~m}$; LRT, $\chi^{2}=2.4, \mathrm{df}=2, \mathrm{p}=0.31$ ).

Our data did not show significant differences in minimum convex polygon area with respect to tag type, neither for NMEA data (BP: $464 \mathrm{~m}^{2}$, NB: $650 \mathrm{~m}^{2}$; LRT, $\left.\chi^{2}=0.9, \mathrm{df}=1, \mathrm{p}=0.33\right)$, nor for PPP data tracks (BP: $579 \mathrm{~m}^{2}$, NB: $632 \mathrm{~m}^{2}$; LRT, $\left.\mathrm{X}^{2}=0.1, \mathrm{df}=1, \mathrm{p}=0.77\right)$. However, note that sample size was very low. For backpacks, polygon areas were larger for PPP than for NMEA positions (NMEA: $547 \mathrm{~m}^{2}$, PPP: $663 \mathrm{~m}^{2}$; LRT, $\chi^{2}=5.5$, $\mathrm{df}=1, \mathrm{p}=0.02)$, but there was no difference in neckband tags (NMEA: $566 \mathrm{~m}^{2}$, NB: $548 \mathrm{~m}^{2}$; LRT, $\chi^{2}=0.01$, $\mathrm{df}=1, \mathrm{p}=0.94)$. Thus, for backpacks the PPP positions were more spread out.

\section{Behavioural classification from accelerometer data}

In the behaviour-annotated examples of static and dynamic acceleration for the backpack tag (Fig. 4a, b) and neckband tag (Fig. 4c, d), the variability in alignment (static acceleration) was less pronounced in backpack than in neckband tags and did not as easily match with behaviours (but see long feeding burst in Fig. 4a). For the neckband, e.g. feeding events were clearly depicted by peaks in the $\mathrm{x}$-axis static acceleration. Note that the $\mathrm{x}$-axis pointed towards the head in the neckbands and was not affected by the regularly occurring, movement induced events of the neckband rotation. In the dynamic acceleration patterns, resting was clearly visible for the backpack as well as the neckband (dynamic acceleration of all axes $=0$ ). Feeding could in this example not be well 

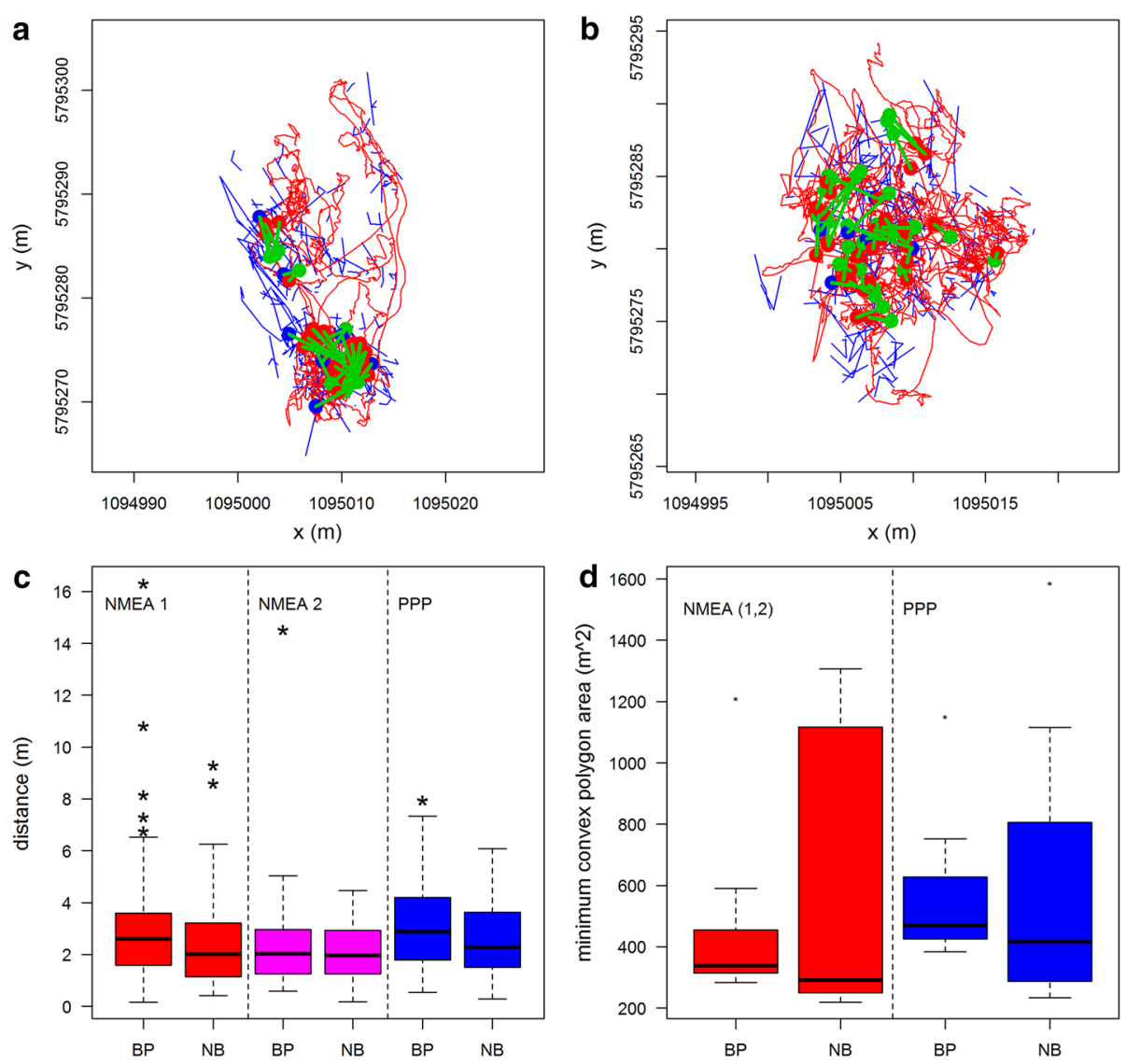

Fig. 3 Example tracks and accuracy statistics for GPS data of backpack (BP) and neckband (NB) tags on geese. a NMEA data (red), PPP data (b/ue) and distances of time-overlapping NMEA or PPP data with exact measures of the Geosystems Total Station (green) for a 10-min track of one goose with a backpack tag. b Same as a, but for a goose with a neckband tag. c Distances of NMEA 1, NMEA 2 and PPP data to exact positions, split for $\mathrm{BP}$ and NB tags. $\mathbf{d}$ Minimum convex polygon area of NMEA and PPP tracks for both tag types. Please see the list of abbreviations for explanations of NMEA $1 / 2$ and PPP. Note that measures in the box plots are not model parameters (as reported in the text), but raw data, and do not account for random factors

discerned from dynamic acceleration of the backpack: similar to walking, it was characterised by a regular wave pattern in the $\mathrm{x}$-axis dynamic acceleration. On the other hand, the dynamic acceleration of the neckband showed rather unique high amplitudes during feeding. However, there are several other peaks that were not easy to explain.

When examining the classification trees, the pitch in the $\mathrm{x}$-axis for backpack tags (Fig. 5a) was a main statistic for the first split of resting/feeding (high pitch) from walking/vigilance (low pitch), indicating that body angle (leaning back or forward) was the best initial classification criteria. Then, on one part of the tree, resting was split off by low $\mathrm{x}$-axis overall dynamic body acceleration (odbaX), i.e. little front/back movement of the tag. At the other part of the tree, vigilance was split off by low odba (very little overall movement) and walking was further split off by high $\mathrm{x}$-axis frequency at the dominant power spectrum (strong wave pattern; fdpsX). The only indication visible for feeding was low $\mathrm{x}$-axis maximum dynamic body acceleration (mdbaX).

For the neckband tag, the classification tree looked very different (Fig. 5b). First, feeding, preening and walking were split off by high odba, indicating a high level of general tag movement. Further, splits by mdbaZ and rollY indicated that preening contained very strong right/ left positional and angular changes. Note that right/ left and front/back movements ( $y$ - and $z$-axes) are not easily discernible, because the neckband tag can freely rotate around the goose's neck. Walking was split off by low mdbaZ and high odbaY, showing the right/left swaying walk of Canada geese. Feeding showed low angular change in the y-axis (rollY). On the other side of the classification, tree resting and vigilance were discerned by 

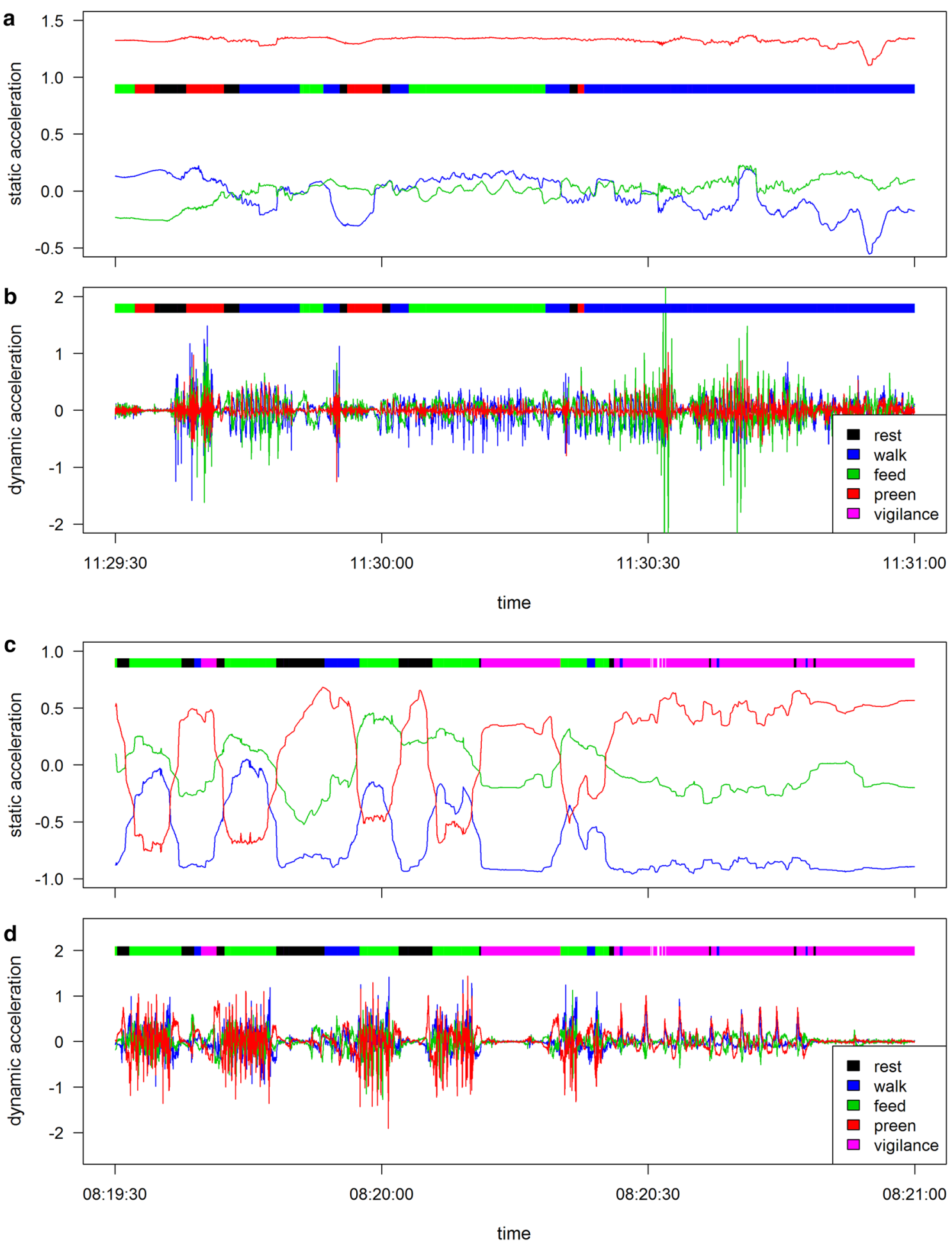

Fig. 4 Example data of static and dynamic acceleration data for both tag types, down-sampled to $20 \mathrm{~Hz}$ resolution. $\mathbf{a}$ Static and $\mathbf{b}$ dynamic acceleration in all three axes ( $x$-blue, $y$-green, $z$-red) of a goose with backpack tag with an overlaid bar of observed behaviour inserted (black rest, blue walk, green feed, red preen, pink vigilance). $\mathbf{c}, \mathbf{d}$ Same as $\mathbf{a}, \mathbf{b}$, but for a goose with neckband tag. Note the differences in scale and differentiability of behaviours by tag type. The accelerometer was fitted into the tags so that for the backpacks $x$ is the reverse of surge, $y$ is the sway and $z$ is the heave. For the neckband on a raised goose neck that means $x$ is the reverse of heave and $y$ and $z$ indicate surge and sway depending on how the tag is turned 


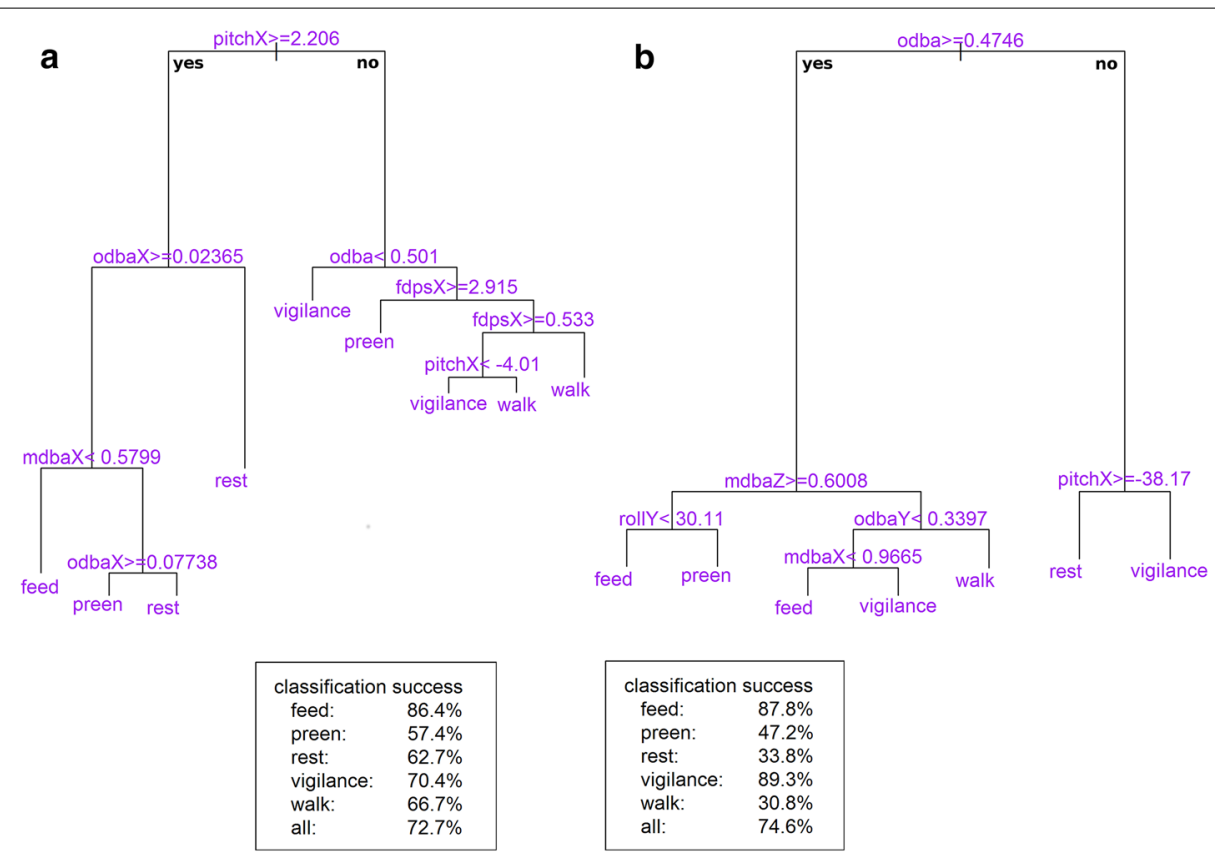

Fig. 5 Final, pruned classification trees of six main behaviours of observed geese as calculated by accelerometer statistics. a Classification tree for backpack tags with a legend of cross-validation success rates for each behaviour separately and an overall value. b Same as a, but for neckband tag data. The acceleration statistics used in the analyses are: pitchX_-body angle along $x$-axis, pitchZ—body angle along z-axis, rollY —-body angle along $y$-axis, mdbaX/mdbaY/mdbaZ—maximum dynamic body acceleration along the $x$-/y-/z-axes, odbaX/odbaY/odbaZ—mean dynamic body acceleration along the $\mathrm{x}$-/y-/z-axes, odba—overall dynamic body acceleration (sum of the previous), dpsX/dps $Y / d p s Z$ - maximum power spectral density of dynamic acceleration along $x$-/y-/Z-axes, fdpsX/fdpsY/fdpsZ-frequency at the maximum power spectral density along the $x$-/y-/Z-axes (for more explanation, see [73])

pitchX, indicating that the difference between the two rather inert behaviours was in body/head angle.

The overall classification success rates of the fitted trees (Fig. 5) were similarly high for both tag types (BP: $72.7 \%$, NB: $74.6 \%$ ). However, feeding and vigilance behaviours were better classified for neckbands than for backpacks, whereas preening, resting and walking were better detected in backpack data (Fig. 5, for details see Additional file 1: Table A1). Thus, neckbands were better at classifying behaviours that were mainly performed with the head, whereas backpacks seem better able to map whole-body behaviours.

\section{Discussion}

We have compared two of the most widely used types of attachment of GPS/accelerometer tags on large waterbirds, for the first time in a way that integrated the quantification of tag-induced adverse behaviour during early habituation, GPS position accuracy and behaviour classification success from accelerometer data. In general, both tag types showed a similar short-term discomfort effect on the birds, GPS accuracy was only slightly better for neckband tags, and overall behavioural classification success from accelerometer data was similar.
Behaviour-specific classification results differed between the two types of tags; neckbands showed better results for behaviours involving head movement such as feeding or vigilance due to their position close to the head, and backpacks were more successful in detecting behaviours such as walking or resting, for which it is important that the tag is closely fixed to the body (not freely moving around the neck). Thus, a decision on the use of neckband or backpack tags for large waterbirds cannot be based on early habituation discomfort of the birds or GPS position accuracy, but should depend on possibly differential long-term habituation and the research question.

Apart from showing that short-term, tag-induced discomfort was similar for both tag types, we have also seen that time since deployment did not influence the geese' behaviours during the first 6 days. This indicates that previously observed habituation to the tags takes longer, up to several weeks or months [54], and might then differ between different tag attachments. This can be important to consider, because one issue of many tracking research is the necessary duration of the study, for how long the animal shall carry a tag and collect data (e.g. foraging movement vs. lifetime tracking). Furthermore, it is important to understand for which time frame tracking 
data are affected by discomfort of the animal and when seemingly normal movement data can be observed.

In the light of animal welfare, a tag should only be mounted on the animal as long as it is working properly [67]. Therefore, drop-off mechanisms and weak links in harnesses have become more widely used [74]. Simple glue-on-feathers has been used for short-term deployments in the past [75], but can damage the feathers or skin of animals. However, if it is desirable that the tag stays on the animal for a long time, the material and attachment methods should be adapted, taking into account habitat conditions and the destructiveness of the animals. Some species of geese are known to destroy harnesses and backpack tags within a short time [61], and there is advice not to use a harness for this species group [58]. However, plastic neckbands are known to have a long retention time [71] and are less accessible for the wearer to inflict damage with its bill. Initial concern regarding neckband icing [76] has been lessened by studies showing that icing is exceptionally rare and does not have long-term fitness consequences for geese [70, 77]. Furthermore, the fact that unique IDs can be inscribed on the outside of a neckband for visual observations is a large advantage when quantifying survival and tag functionality.

External tags have been reported to have no significant long-term effect on animals [59, 71, 78], but there have also been cases showing various negative effects on animal behaviour and survival $[22,43,63,65,79,80]$. Such effects can be intensified if the animal is flying or moving through water, depending on tag placement $[47,48]$. It is possible that neckband tags have a higher aerodynamic resistance during flight and that their placement away from the centre of gravity might affect the bird's balance, leading to higher flight costs. On the other hand, the harness of a backpack tag is likely to cause abrasions and hamper flapping of the wings, which is especially important for geese that almost exclusively use flapping flight. It was not possible for us to incorporate flight behaviour in this study, and there are, as far as we know, no other studies that compare the differences of negative effects of neckbands versus backpacks during flight or diving. However, from field experience it seems that the longevity of wild geese with neckband tags is higher, possibly due to better manoeuvrability during flight (AK, unpublished data). Furthermore, fat accumulation for migration can negatively affect body harness fit of backpacks, but is not problematic for neckbands, as neck size does not change.

Habituation to tags might also depend on the handling time and procedures during deployment, in which context we consider neckbands more suitable as they are more 'standardised' and quickly to attach. However, it is important to realise that our study was performed with captive animals and that the effects of being handled and carrying the tags on the behaviour of wild birds might differ. They are usually more constrained in food availability, and the need for vigilance for predators is higher. Therefore, tag-induced discomfort might not be affecting their time budget as much, and our findings of extra time spent preening and shaking are conservative measures. On the other hand, they might be initially more stressed by the tag than captive geese that are somewhat used to being handled. However, we are confident that the general conclusions of our comparative study can be transferred to wild waterbirds.

With awareness that external devices are most likely affecting animals (at least short term during habituation [54]), it is even more important to ensure the highest possible quantity and quality of collected data. For long-term studies, the extension of time in functionality has successfully been achieved by including solar cells for energy provision, so that tag running times are not time-limited by battery power. Regarding data quality, our results suggest that GPS accuracy from the particular backpack tags of this study was generally lower and more strongly improved by filtering and SBAS augmentation than neckband tags. Thus, for data sets that are not continuously of NMEA 2 type, it seems advisable to prefer neckband tags to obtain higher GPS accuracy. These findings differ from earlier results on ARGOS reception and lower accuracy of neckbands than backpacks [58]. However, in that study the antennas of the neckbands pointed down the neck of the goose, which has been shown to be problematic [39].

Furthermore, signal frequency, antenna type and orientation will have a profound effect on device performance, making comparisons difficult. The signal reception patterns of our tags' helical antennas in relation to the GPS satellites would have affected the device performance in ways that are too complex to explore here, but our results are probably influenced most strongly by antenna characteristics. Helical antennas were chosen because their reception pattern is omnidirectional, and their orientation has less effect on received signal strength than would the patch antennas that are normally used with GPS receivers because they have higher gain. We did not test the effect of antenna orientation during flight. However, if the orientation of the neckband tag during flight results in the antenna hanging under the bird's outstretched neck, the ability of the GPS receiver to acquire satellites is likely to be reduced. In contrast, the orientation of a back-mounted tag is likely to remain much the same during flight, and indeed the height of the bird and clear line of sight to GPS satellites would probably improve receiver performance. 
As more global satellite navigation systems join America's GPS (e.g. Russia's GLONASS and Europe's Galileo) in becoming available for widespread use, and augmentation of GPS accuracy is possible in different ways (differential GPS, SBAS, filtering), improved position data and their applicability for ecological research should be evaluated. For different research questions, GPS fix rate, accuracy or precision is of varying importance. For example, studies on habitat selection require GPS positions of high accuracy to allow for correct overlap with e.g. remote sensing data, whereas studies about individual behaviour or group movement need high GPS precision. Here, we take a first step to also raise ecologists' attention to the likelihood that GPS positions from standard devices are augmented by some form of smoothing algorithm (probably based on an extended Kalman filter) before being output from the device. Rapidly sampled individual locations output from a GPS tag are unlikely to be statistically independent, and the type of filter/platform setting applied (e.g. stationary, pedestrian walking, motor vehicle) will influence the data. As the smoothing algorithms depend on fast sampling rates, their influence on infrequent GPS locations is less, probably negligible. However, if a fast sampling rate is used to test the accuracy of a stationary GPS tag, the results may not be representative of the performance on the animal [81]. Therefore, the use of raw GPS data might be advisable for high-frequency GPS tracking studies.

In most studies, especially working with small species, tag weight is most important $[42,43,49]$ and often limits data quality and quantity options. However, we want to stress here that tag weight cannot be considered independent of the tag design and tag attachment method [47]. A device mounted on body appendages such as leg, tail or head should ideally be somewhat lighter than a tag attached to the back of an animal or implanted [64, 82], which is supported by the whole body mass. For large waterbirds, this seems to be less of an issue, the tags used here are quite heavy in absolute terms, but still $<1.5 \%$ of the body weight.

The integration of extra sensors into GPS tags is improving usability of position data for many applications. Accelerometer measurements are one example that is gaining more attention [12, 13], and we show that for the best use of accelerometer data it is critical to compare different means of attachment and placement $[51,83]$. An accelerometer records the movements of the parts of the body directly underneath the tag, and as body parts move differently for the various behaviours, it is important to have a clear idea which tag placement can give the most significant acceleration data to detect the respective behaviour. Thus, depending on which type of behaviour is relevant for the attempted study, unconventional placement of small tags might be most effective and will improve the scope of accelerometer data sets even more.

We are aware that there might always be limitations to animal tracking $[1,20]$. Some species simply are too small, do not tolerate handling stress or are hard to catch. However, by pushing the technological limits, animal tracking will be refined into a truly revolutionary tool for wildlife research. Ecologists should use the smallest tags with the least effect on the animal's behaviour giving the best quality data for answering the research questions posed by various disciplines. By extracting natural, objective time budgets and discerning small-scale changes in movement and other behaviours besides the animal's location, we will be able to explore an animal's true natural behaviour and apply this knowledge to conservation, management or models of disease spread.

\section{Conclusion}

We have shown that captive Canada geese with backpack or neckband tags exhibit discomfort behaviours at a similar level during a short habituation period. GPS accuracy and general behaviour classification success based on accelerometer data from both tag types were similar. However, some behaviour types were better recognised by neckbands, others by backpacks. Therefore, we advise that the selection of either type of tag attachment method for large waterbirds should depend on the research question, including focal behaviours and necessary tag retention time.

\section{Additional file}

Additional file 1: Table A1. Success rates of behaviour classification trees for $\mathbf{a}$ backpack and $\mathbf{b}$ neckband tag accelerometer statistics.

\section{Abbreviations}

NMEA: National Marine Electronics Association; : Standard format used for processed GPS data that are directly obtained from a GPS tracking device. Usually, the GPS positions are filtered by platform settings that are often based on the extended Kalman filter to improve accuracy [34]. Here, the platform settings were 'pedestrian walking'; NMEA 1: NMEA data that are filtered as 'pedestrian walking, but where the SBAS correction signal has not been received to additionally improve the positions; NMEA 2: NMEA data that are filtered as 'pedestrian walking' and for which the GPS tag had received the SBAS correction signal for improvement of the positions with differential methods; PPP: Precise point positions. GPS positions that were extracted by post-processing raw GPS data with the use of SBAS correction signals obtained from the EDAS service. These positions were not filtered.

\section{Authors' contributions}

AK, HHTP, BHC and BAN designed the study. JB and BHC developed and suCcessively refined the GPS/accelerometer tags. AK, MN, GJDMM devised the different methods of tag attachment, and AK, MN and BAN performed the study. AK, MN and JB analysed the different data sets, and AK, FvL, FdB and $B A N$ refined the results. The manuscript was written by AK, and all authors contributed to refining the text and content. All authors read and approved the final manuscript. 


\begin{abstract}
Author details
1 Department of Animal Ecology, Netherlands Institute of Ecology (NIOOKNAW), PO Box 50, 6700 AB Wageningen, The Netherlands. ${ }^{2}$ Department of Migration and Immuno-ecology, Max Planck Institute for Ornithology, Am Obstberg 1, 78315 Radolfzell, Germany. ${ }^{3}$ Department of Biology, University of Konstanz, Universitätsstraße 10, 78464 Constance, Germany. ${ }^{4}$ Biotrack Ltd., 52 Furzebrook Road, Wareham BH20 5AX, UK. ${ }^{5}$ Team Animal Ecology, Ecotoxicology and Wildlife Management, Alterra Wageningen-UR, Droevendaalsesteeg 3a, 6708 PB Wageningen, Netherlands. ${ }^{6}$ Resource Ecology Group, Wageningen University, Droevendaalsesteeg 3a, 6708 PB Wageningen, The Netherlands. ${ }^{7}$ Computational Geo-Ecology, Department of Science, Institute for Biodiversity and Ecosystem Dynamics, University of Amsterdam, PO Box 94248, 1090 GE Amsterdam, The Netherlands.
\end{abstract}

\section{Acknowledgements}

This study was performed as part of the E-Track project (full title: 'EGNOS and EDAS enhanced tracking of animal movement and behaviour') that was carried out in the context of the Galileo FP7 R\&D programme supervised by the GSA (nr. 277697-2). We want to thank Noldus Information Technology BV and namely Lucas Noldus for coordination of the project and all helpful comments on the work presented here. We kept the geese and performed the experiments under Protocol NIOO 12.10 that was approved by the Animal Experimentation Committee of the KNAW. We are grateful to Berend Voslamber for ringing and sexing the geese and to Martin Wikelski, Willem Bouten and an anonymous reviewer for helpful comments on the manuscript.

\section{Competing interests}

The authors declare that they have no competing interests.

Received: 11 December 2015 Accepted: 8 April 2016

Published online: 04 May 2016

\section{References}

1. Kays R, Crofoot MC, Jetz W, Wikelski M. Terrestrial animal tracking as an eye on life and planet. Science. 2015;348(6240):1222. doi:10.1126/science. aaa2478.

2. Cagnacci F, Boitani L, Powell RA, Boyce MS. Theme Issue Challenges and opportunities of using GPS-based location data in animal ecology. Philos Trans R Soc B Biol Sci. 2010;365(1550):2155. doi:10.1098/rstb.2010.0098.

3. Bridge ES, Thorup K, Bowlin MS, Chilson PB, Diehl RH, Fleron RW, et al. Technology on the move: recent and forthcoming innovations for tracking migratory birds. Bioscience. 2011;61(9):689-98. doi:10.1525/ bio.2011.61.9.7.

4. Cagnacci F, Boitani L, Powell RA, Boyce MS. Animal ecology meets GPSbased radiotelemetry: a perfect storm of opportunities and challenges. Philos Trans R Soc B Biol Sci. 2010;365(1550):2157-62. doi:10.1098/ rstb.2010.0107.

5. Tomkiewicz SM, Fuller MR, Kie JG, Bates KK. Global positioning system and associated technologies in animal behaviour and ecological research. Philos Trans R Soc B Biol Sci. 2010;365(1550):2163-76. doi:10.1098/ rstb.2010.0090.

6. Wilmers CC, Nickel B, Bryce CM, Smith JA, Wheat RE, Yovovich V. The golden age of bio-logging: how animal-borne sensors are advancing the frontiers of ecology. Ecology. 2015;96(7):1741-53. doi:10.1890/14-1401.1.

7. Cooke SJ, Hinch SG, Wikelski M, Andrews RD, Kuchel LJ, Wolcott TG, et al. Biotelemetry: a mechanistic approach to ecology. Trends Ecol Evol. 2004;19(6):334-43. doi:10.1016/j.tree.2004.04.003.

8. Ropert-Coudert Y, Wilson RP. Trends and perspectives in animalattached remote sensing. Front Ecol Environ. 2005;3(8):437-44. doi:10.2307/3868660

9. Nathan R, Spiegel O, Fortmann-Roe S, Harel R, Wikelski M, Getz WM. Using tri-axial acceleration data to identify behavioral modes of free-ranging animals: general concepts and tools illustrated for griffon vultures. J Exp Biol. 2012;215(6):986-96. doi:10.1242/jeb.058602.

10. Wilson RP, White CR, Quintana F, Halsey LG, Liebsch N, Martin GR, et al. Moving towards acceleration for estimates of activity-specific metabolic rate in free-living animals: the case of the cormorant. J Anim Ecol. 2006;75(5):1081-90. doi:10.1111/j.1365-2656.2006.01127.x.
11. Yoda K, Naito Y, Sato K, Takahashi A, Nishikawa J, Ropert-Coudert Y, et al. A new technique for monitoring the behaviour of free-ranging Adelie penguins. J Exp Biol. 2001;204(4):685-90.

12. Brown DD, Kays R, Wikelski M, Wilson RP, Klimley AP. Observing the unwatchable through acceleration logging of animal behaviour. Anim Biotelem. 2013;1:20. doi:10.1186/2050-3385-1-20.

13. Wilson RP, Grundy E, Massy R, Soltis J, Tysse B, Holton M, et al. Wild state secrets: ultra-sensitive measurement of micro-movement can reveal internal processes in animals. Front Ecol Environ. 2014;12(10):582-7. doi:10.1890/140068.

14. Frair JL, Fieberg J, Hebblewhite M, Cagnacci F, DeCesare NJ, Pedrotti L. Resolving issues of imprecise and habitat-biased locations in ecological analyses using GPS telemetry data. Philos Trans R Soc B Biol Sci. 2010;365(1550):2187-200. doi:10.1098/rstb.2010.0084.

15. Greenwood RJ, Sargeant AB. Influence of radio packs on captive mallards and blue-winged teal. J Wildl Manag. 1973;37(1):3-9. doi:10.2307/3799732.

16. Hebblewhite M, Haydon DT. Distinguishing technology from biology: a critical review of the use of GPS telemetry data in ecology. Philos Trans R Soc B Biol Sci. 2010;365(1550):2303-12. doi:10.1098/ rstb.2010.0087.

17. Hulbert IAR, French J. The accuracy of GPS for wildlife telemetry and habitat mapping. J Appl Ecol. 2001;38(4):869-78. doi:10.1046/j.1365-2664.2001.00624.x.

18. Barron DG, Brawn JD, Weatherhead PJ. Meta-analysis of transmitter effects on avian behaviour and ecology. Methods Ecol Evol. 2010;1 (2):180-7. doi:10.1111/j.2041-210X.2010.00013.x.

19. Calvo B, Furness RW. A review of the use and the effects of marks and devices on birds. Ringing Migr. 1992;13(3):129-51.

20. McIntyre T. Animal telemetry: tagging effects. Science. 2015;349(6248):596-7.

21. Wilson RP, McMahon CR. Measuring devices on wild animals: what constitutes acceptable practice? Front Ecol Environ. 2006;4(3):147-54 doi:10.1890/1540-9295(2006)004[0147:MDOWAW]2.0.CO;2.

22. Bowlin MS, Henningsson P, Muijres FT, Vleugels RHE, Liechti F, Hedenstrom A. The effects of geolocator drag and weight on the flight ranges of small migrants. Methods Ecol Evol. 2010;1 (4):398-402. doi:10.1111/j.2041-210X.2010.00043.x.

23. Murray $D L$, Fuller MR. A critical review of the effects of marking on the biology of vertebrates. In: Boitani L, Fuller T, editors. Techniques in animal ecology: controversies and consequences. New York: Columbia University Press; 2000. p. 5-64

24. Cargnelutti B, Coulon A, Hewison AJM, Goulard M, Angibault J-M, Morellet N. Testing global positioning system performance for wildlife monitoring using mobile collars and known reference points. J Wild Manag. 2007;71(4):1380-7. doi:10.2193/2006-257.

25. Recio MR, Mathieu R, Denys P, Sirguey P, Seddon PJ. Lightweight GPS-tags, one giant leap for wildlife tracking? An assessment approach. PLOS ONE. 2011. doi:10.1371/journal.pone.0028225.

26. DeCesare NJ, Squires JR, Kolbe JA. Effect of forest canopy on GPS-based movement data. Wildl Soc Bull. 2005;33(3):935-41. doi:10.2193/0091-7648(2005)33[935:EOFCOG]2.0.CO;2.

27. D'Eon RG, Serrouya R, Smith G, Kochanny CO. GPS radiotelemetry error and bias in mountainous terrain. Wildl Soc Bull. 2002;30(2):430-9.

28. Fryxell JM, Hazell M, Borger L, Dalziel BD, Haydon DT, Morales JM, et al. Multiple movement modes by large herbivores at multiple spatiotemporal scales. Proc Natl Acad Sci USA. 2008;105(49):19114-9. doi:10.1073/ pnas.0801737105.

29. Parsons MB, Gillespie TR, Lonsdorf EV, Travis D, Lipende I, Gilagiza B, et al. Global positioning system data-loggers: a tool to quantify fine-scale movement of domestic animals to evaluate potential for zoonotic transmission to an endangered wildlife population. PLOS ONE. 2014. doi:10.1371/journal.pone.0110984.

30. de Weerd N, van Langevelde F, van Oeveren H, Nolet BA, Kolzsch A, Prins $H H T$, et al. Deriving animal behaviour from high-frequency GPS: tracking cows in open and forested habitat. PLoS ONE. 2015. doi:10.1371/journal. pone. 0129030 .

31. Gurarie E, Andrews RD, Laidre KL. A novel method for identifying behavioural changes in animal movement data. Ecol Lett. 2009;12(5):395-408. doi:10.1111/j.1461-0248.2009.01293.x. 
32. Patterson TA, Thomas L, Wilcox C, Ovaskainen O, Matthiopoulos J. State-space models of individual animal movement. Trends Ecol Evol. 2008;23(2):87-94. doi:10.1016/j.tree.2007.10.009.

33. Courses E, Surveys T. Sigma-point filters: an overview with applications to integrated navigation and vision assisted control. In: Nonlinear statistical signal processing workshop: classical, unscented and particle filtering methods. IEEE; 2006.

34. u-blox: u-blox 6 receiver description. User manual. GPS.G6-SW-10018-F revision for FW 7.03. www.u-blox.com (2013).

35. Rempel RS, Rodgers AR. Effects of differential correction on accuracy of a GPS animal location system. JWildl Manag. 1997;61(2):525-30. doi:10.2307/3802611.

36. Felski A, Nowak A, Wozniak T. Accuracy and availability of EGNOS—results of observations. Artif Satell. 2011;46:111-8.

37. Miesikowiski M, Nowak A, Specht C, Oszczak B. EGNOS-accuracy performance in Poland. Ann Navig. 2006;11:63-72.

38. Witte TH, Wilson AM. Accuracy of WAAS-enabled GPS for the determination of position and speed over ground. J Biomech. 2005;38(8):1717-22. doi:10.1016/j.jbiomech.2004.07.028.

39. D'Eon RG, Delparte D. Effects of radio-collar position and orientation on GPS radio-collar performance, and the implications of PDOP in data screening. J Appl Ecol. 2005;42(2):383-8. doi:10.1111/j.1365-2664.2005.01010.x.

40. Obrecht HH, Pennycuick CJ, Fuller MR. Wind-tunnel experiments to assess the effect of back-mounted radio transmitters on bird body drag. J Exp Biol. 1988;135:265-73.

41. Vandenabeele SP, Shepard ELC, Gremillet D, Butler PJ, Martin GR, Wilson RP. Are bio-telemetric devices a drag? Effects of external tags on the diving behaviour of great cormorants. Mar Ecol Prog Ser. 2015;519:239-49. doi:10.3354/meps11058.

42. Brander RB, Cochran WW. Radio location telemetry. In: Giles RHJ, editor. Wildlife management techniques. Washington, DC: Wildlife Society; 1969. p. 95-103.

43. Gessaman JA, Nagy KA. Transmitter loads affect the flight speed and metabolism of homing pigeons. Condor. 1988;90(3):622-68.

44. Aldridge HDJN, Brigham RM. Load carrying and maneuverability in an insectivorous bat-a test of the 5-percent rule of radio-telemetry. J Mammal. 1988;69(2):379-82. doi:10.2307/1381393.

45. Kesler DC, Raedeke AH, Foggia JR, Beatty WS, Webb EB, Humburg DD, et al. Effects of satellite transmitters on captive and wild mallards. Wildl Soc Bull. 2014;38(3):557-65. doi:10.1002/wsb.437.

46. Vandenabeele SP, Grundy E, Friswell MI, Grogan A, Votier SC, Wilson RP. Excess baggage for birds: inappropriate placement of tags on gannets changes flight patterns. PLoS ONE. 2014. doi:10.1371/journal. pone.0092657.

47. Vandenabeele SP, Shepard EL, Grogan A, Wilson RP. When three per cent may not be three per cent; device-equipped seabirds experience variable flight constraints. Mar Biol. 2012;159(1):1-14. doi:10.1007/ s00227-011-1784-6.

48. Pennycuick CJ, Fast PLF, Ballerstaedt N, Rattenborg N. The effect of an external transmitter on the drag coefficient of a bird's body, and hence on migration range, and energy reserves after migration. J Ornithol. 2012;153(3):633-44. doi:10.1007/s10336-011-0781-3.

49. O'Mara MT, Wikelski M, Dechmann DKN. 50 Years of bat tracking: device attachment and future directions. Methods Ecol Evol. 2014;5(4):311-9. doi:10.1111/2041-210x.12172.

50. Kokubun N, Kim J-H, Shin H-C, Naito Y, Takahashi A. Penguin head movement detected using small accelerometers: a proxy of prey encounter rate. J Exp Biol. 2011;214(22):3760-7. doi:10.1242/jeb.058263.

51. Preston T, Baltzer W, Trost S. Accelerometer validity and placement for detection of changes in physical activity in dogs under controlled conditions on a treadmill. Res Vet Sci. 2012;93(1):412-6. doi:10.1016/j. rvsc.2011.08.005.

52. Hawkes LA, Balachandran S, Batbayar N, Butler PJ, Chua B, Douglas DC, et al. The paradox of extreme high-altitude migration in bar-headed geese Anser indicus. Proc R Soc Biol Sci Ser B. 2013;280(1750):1-8.

53. Kölzsch A, Bauer S, de Boer R, Griffin L, Cabot D, Exo K-M, et al. Forecasting spring from afar? Timing of migration and predictability of phenology along different migration routes of an avian herbivore. J Anim Ecol. 2015;84(1):272-83. doi:10.1111/1365-2656.12281.
54. Nuijten RJM, Kolzsch A, van Gils JA, Hoye BJ, Oosterbeek K, de Vries PP, et al. The exception to the rule: retreating ice front makes Bewick's swans Cygnus columbianus bewickii migrate slower in spring than in autumn. J Avian Biol. 2014;45(2):113-22. doi:10.1111/j.1600-048X.2013.00287.x.

55. van Wijk RE, Kölzsch A, Kruckenberg H, Ebbinge BS, Muskens GJDM, Nolet BA. Individually tracked geese follow peaks of temperature acceleration during spring migration. Oikos. 2012;121(5):655-64. doi:10.1111/j.1600-0706.2011.20083.x.

56. Mandel JT, Bildstein KL, Bohrer G, Winkler DW. Movement ecology of migration in turkey vultures. Proc Natl Acad Sci USA. 2008;105(49):191027. doi:10.1073/pnas.0801789105.

57. Madsen J, Christensen TK, Balsby TJS, Tombre IM. Could have gone wrong effects of abrupt changes in migratory behaviour on harvest in a waterbird population. PLoS ONE. 2015. doi:10.1371/journal.pone.0135100.

58. Blouin F, Giroux JF, Ferron J, Gauthier G, Doucet GJ. The use of satellite telemetry to track Greater Snow Geese. J Field Ornithol. 1999;70(2):187-99.

59. Glahder CM, Fox AD, Walsh AJ. Effects of fitting dummy satellite transmitters to Greenland White-fronted geese Anser albifrons flavirostris. Wildfowl. 1998:48:88-97.

60. Malecki RA, Sheaffer SE, Walsh A, Stroud D. Harnessing those pesky Anser species. Goose Bull. 2011;12:19-24.

61. Voslamber B, Podhrazsky M, Boudewijn T. Harnesses on geese. Goose Bull. 2010;11:35-40.

62. Sheaffer SE, Rusch DH, Humburg DD, Lawrence JS, Zenner GG, Gillespie MM, et al. Survival, movements, and harvest of eastern prairie population Canada geese. Wildl Monogr. 2004;156:1-54.

63. Enstipp MR, Frost J, Hollmen TE, Andrews RD, Frost C. Two methods of radio transmitter attachment and their effects on the behavior and energetics of captive long-tailed ducks (Clangula hyemalis) during winter. Anim Biotelem. 2015;3:36.

64. Garrettson PR, Rohwer FC, Moser EB. Effects of backpack and implanted radiotransmitters on captive blue-winged teal. J Wildl Manag. 2000;64(1):216-22. doi:10.2307/3802993.

65. Schmutz JA, Morse JA. Effects of neck collars and radiotransmitters on survival and reproduction of emperor geese. J Wildl Manag. 2000;64(1):231-7. doi:10.2307/3802995.

66. Small RJ, Rusch DH. Backpacks vs. ponchos-survival and movements of radio-marked ruffed grouse. Wildl Soc Bull. 1985;13(2):163-5.

67. Zutphen LFM, Baumans V, Beynen AC. Principles of laboratory animal science, revised edition: a contribution to the humane use and care of animals and to the quality of experimental results. Amsterdam: Elsevier; 2001.

68. Guay PJ, Mulder RA. Do neck-collars affect the behaviour and condition of Black Swans (Cygnus atratus)? Emu. 2009;109(3):248-51. doi:10.1071/ mu09020.

69. Macinnes CD, Dunn EH. Effects of neck bands on Canada geese nesting at the McConnell River. J Field Ornithol. 1988;59(3):239-46.

70. Madsen J, Kuijken E, Kuijken-Verscheure C, Hansen F, Cottaar F. Incidents of neckband icing and consequences for body condition and survival of pink-footed geese Anser brachyrhynchus. Wildl Biol. 2001;7(1):49-53.

71. Johnson IP, Sibly RM. Effects of plastic neck collars on the behavior and breeding performance of geese and their value for distant recognition of individuals. Ringing Migr. 1989;10(1):58-62.

72. Demers F, Giroux JF, Gauthier G, Bety J. Effects of collar-attached transmitters on behaviour, pair bond and breeding success of snow geese Anser caerulescens atlanticus. Wildl Biol. 2003;9(3):161-70.

73. Shamoun-Baranes J, Bom R, van Loon EE, Ens BJ, Oosterbeek K, Bouten W. From sensor data to animal behaviour: an oystercatcher example. PLoS ONE. 2012. doi:10.1371/journal.pone.0037997.

74. Karl BJ, Clout MN. An improved radio transmitter harness with a weak link to prevent snagging. J Field Ornithol. 1987;58(1):73-7.

75. Diemer KM, Wheeler HE, Nocera JJ. Retention rates of glue-attached radio-transmitters on two small bird species with contrasting life histories. Wilson J Ornithol. 2014;126(1):39-46.

76. Zicus MC, Schultz DF, Cooper JA. Canada goose mortality from neckband icing. Wildl Soc Bull. 1983;11(3):286-90.

77. Fox AD, Walsh AJ, Weegman MD, Bearhop S, Mitchell C. Spring ice formation on goose neck collars: effects on body condition and survival in Greenland white-fronted geese Anser albifrons flavirostris. Eur J Wildl Res. 2014;60(5):831-4. doi:10.1007/s10344-014-0835-y. 
78. Clausen KK, Madsen J. Effects of neckbands on body condition of migratory geese. J Ornithol. 2014;155(4):951-8. doi:10.1007/s10336-014-1080-6.

79. Paquette GA, Devries JH, Emery RB, Howerter DW, Joynt BL, Sankowsk TP. Effects of transmitters on reproduction and survival of wild mallards. J Wildl Manag. 1997;61(3):953-61. doi:10.2307/3802205.

80. Pietz PJ, Krapu GL, Greenwood RJ, Lokemoen JT. Effects of harness transmitters on behavior and reprodution of wild mallards. J Wildl Manag. 1993;57(4):696-703. doi:10.2307/3809068.

81. Wilson AM, Lowe JC, Roskilly K, Hudson PE, Golabek KA, McNutt JW. Locomotion dynamics of hunting in wild cheetahs. Nature. 2013:498(7453):185. doi:10.1038/nature12295.
82. Hooijmeijer JCEW, Gill RE Jr, Mulcahy DM, Tibbitts TL, Kentie R, Gerritsen GJ, et al. Abdominally implanted satellite transmitters affect reproduction and survival rather than migration of large shorebirds. J Ornithol. 2014;155(2):447-57. doi:10.1007/s10336-013-1026-4.

83. Gleiss AC, Wilson RP, Shepard ELC. Making overall dynamic body acceleration work: on the theory of acceleration as a proxy for energy expenditure. Methods Ecol Evol. 2011;2(1):23-33. doi:10.1111/j.2041-210X.2010.00057.x.

\section{Submit your next manuscript to BioMed Central and we will help you at every step:}

- We accept pre-submission inquiries

- Our selector tool helps you to find the most relevant journal

- We provide round the clock customer support

- Convenient online submission

- Thorough peer review

- Inclusion in PubMed and all major indexing services

- Maximum visibility for your research

Submit your manuscript at www.biomedcentral com/submit 